\title{
POR UMA ARQUITETURA AO SERVIÇO DA MUSEOLOGIA CONTEMPORÂNEA
}

Mário Moutinho ${ }^{1}$

Os Museus constituem atualmente, na maioria dos países, uma parte da atividade cultural onde se desenvolvem os desafios cada vez mais centrais das problemáticas da identidade, do lazer, da educação e da inclusão socioeconómica.

Em Portugal o fim do século XX foi certamente o período em que o pensamento museológico, a par do forte aumento do número dos museus, mais cresceu. Trata-se de iniciativas essencialmente de âmbito local com origem no associativismo e nas políticas culturais e turísticas dos municípios. Estas iniciativas correspondem a um complexo conjunto de motivações, de abordagens e de diversas formas de entender as questões patrimoniais tanto ao nível da patrimonialização como da musealização. É pois legítimo encontrar um panorama multifacetado desta museologia, a qual se apoia atualmente, por um lado no enquadramento das políticas públicas para a cultura, tanto de âmbito nacional como europeu, (POC, Programas LEADER, INTERREG etc.) e por outro lado numa crescente atenção que as universidades portuguesas têm dado à questão da qualificação dos recursos humanos. São várias as Universidade, subsidiadas e autofinanciadas, que oferecem cursos de pós graduação, de Mestrado e mais recentemente de Doutoramento em Museologia. Seguindo conceitos, métodos e objetivos diversos, mas que no seu todo oferecem um vasto leque de escolha entre a museologia tradicional voltada para as coleções e

\footnotetext{
${ }^{1}$ Professor no Departamento de Museologia da Universidade Lusófona de Lisboa' mario.moutinho@ulusofona.pt
} 
a museologia mais envolvida com as questões da inclusão social e do desenvolvimento. Isoladas estão as pessoas que ainda não assumiram que a qualidade de desempenho de uma instituição, depende da qualificação do seu Capital Humano e, consequentemente, da qualidade da sua formação teórica e prática.

No último quartel do século XX as práticas museológicas e os conceitos que lhes estão ligados sofreram alterações profundas. Este processo procurou adaptar as instituições museológicas às mutações da própria sociedade, sempre no sentido de levar os museus a participarem ativamente em favor das sociedades que Ihes davam e dão vida. As práticas correntemente inscritas na ideia de Nova Museologia ao longo dos anos foram incorporando novas abordagens e novos conceitos que atualmente dão corpo à Sociomuseologia, na qual se busca uma visão mais abrangente e inclusiva destes processos.

Isto não significa que todos os museus tenham sido sempre sensíveis aos contextos de mudança, pelo que hoje encontramos museus que se autoexcluíram dos processos de participação e na verdade vegetam lamentavelmente sem que neles se vislumbre o exercício de qualquer utilidade para com o resto da sociedade.

Por isso, esses museus, reduzem geralmente a sua atividade à manutenção de uma exposição permanente sem ideias, sem rumo, de puro "exibicionismo" como diria Hugues de Varine "disneylandificação e que por isso mesmo, envelhecem ainda mais rapidamente.

E não corro grande risco de errar se pretender que para a generalidade dos autores de projectos de arquitectura de museus é esta a ideia dominante.

Os museus seriam apenas embalagens dentro das quais se exibem objectos e onde acessoriamente se guardam e conservam todos os outros objectos que não cabem nas exposições.

Mas a realidade é outra e os desafios para a arquitectura são aqueles que resultam da necessidade de reconhecer que os museus no tempo contemporâneo não correspondem aos velhos estereótipos. 
O projecto de arquitectura deverá por isso integrar a realidade e diversidade dos conceitos de museologia para os quais é necessário criar espaços permanentes e ou temporários.

Na verdade há muito que deixou de existir um modelo único de Museu igual à ideia de coleção, de edifício e de público, para se assumir o museu com um lugar central dos conceitos de património (s) território e população.

Desenvolveram-se novos modelos de gestão não hierarquizados e assumiu-se o alargamento da noção de património, e a consequente redefinição de "objeto museológico ".

Este processo de abandono de uma ideia única de Museu é determinado pela ambiguidade desta situação, que arrasta conflitos, difíceis em muitos casos de resolver.

Os conceitos de Sociomuseologia de forma mais abrangente e alguns dos conceitos ligados à nova museologia tais como Ecomuseologia e Economuseologia, expressam diferentes formas dos museus se posicionarem no mundo contemporâneo. Partiu-se da ideia de que o museu é "uma instituição permanente, sem finalidade lucrativa, ao serviço da sociedade e do seu desenvolvimento, aberta ao público e que realiza investigações que dizem respeito aos testemunhos materiais do homem e do seu meio ambiente, adquire os mesmos, conserva-os, transmite-os e expõenos especialmente com intenções de estudo, da educação e de deleite". Os museus bem comportados do ICOM!

Mas para além desses Museus designados como tal passaram também a ser reconhecidas como museus as instituições ou organizações com fins não lucrativos que exercem atividades de investigação, educativas, de formação, de documentação e outras relacionadas com os Museu ou com a museologia (Estatutos do Conselho Internacional dos Museu 1995)

É certo, que é cada vez mais frequente constatar que uma nova geração de Museus se organizam e definem os seus programas de atividades perspetivados, como recurso para o desenvolvimento. Preocupam-se com os problemas do mundo em que vivem promovendo o emprego, fomentando novas formas de turismo, 
revitalizando e criando indústrias e reforçando identidades. Cada dia mais os museus procuram diferentes formas de sustentabilidade e estão atentos à promoção do desenvolvimento humano e da coesão social e económica

E para este museu será de bom senso pretender uma nova abordagem arquitetonica que dê conta das novas realidades museológicas.

A museologia como meio de comunicação é cada vez mais entendida como um recurso exterior ao Museu. E se assim for, teremos de considerar a distinção entre a museografia, como tudo o que diz respeito ao Museu, da expografia entendida como uma escrita, de algum modo inovadora, como sendo esse meio de comunicação.

Se o Museu reconhece e é fruto das multifacetadas Redes, que lhe dá vida, terá forçosamente que admitir a alteração do lugar de cada um ocupa neste processo e encontrar novos rumos de comunicação que tenham em consideração os que produzem e consomem o discurso museológico são parte do mesmo processo.

O grau de autonomia de cada pessoa, que hoje caracteriza a nossa sociedade leva os indivíduos cada vez mais, a não se submeterem tão facilmente a discursos autoritários e padronizados.

E neste campo importa que a arquitetura proponha soluções espaciais e construtivas que favoreçam esta nova realidade.

A ideia de exposição temporária é hoje um dado adquirido e nenhum museu que se pretenda moderno ousaria ignorar este facto. Por outro lado a montagem de exposições sobre problemas da atualidade, museus da sociologia, da psicologia ou da globalização, também são uma realidade e estruturam por si sós a programação museológica de pequenas e grandes instituições, ou de pequenos museus de comunidade e de redes onde as exposições são essencialmente o partilhado processo de apreensão da realidade e catalisadoras de vontades, aspirações e desejos de intervenção.

Faltará pois ter em consideração que mais tarde ou mais cedo os museus terão de deixar pelo menos em parte esta obsessão pelo 
passado, pelo definitivo, para se dotarem de espaços que permitam que cada Museu em que cada dia possa mudar as suas exposições de acordo com a vida de cada dia.

É neste contexto que se torna necessário analisar a contribuição da arquitectura para o campo da museologia, ou melhor das diferentes conceituações da museologia contemporânea.

Importa também distinguir a abordagem arquitectónica pelo menos dos seguintes pontos de vista

Projectos para edifícios novos;

Projectos de adaptação de edifícios para usos museológicos;

Projectos expográficos;

Relativamente aos edifícios novos, é por demais evidente que o objeto arquitetonico cresce á revelia de programas museológicos. Uma espécie de domínio da arquitectura onde a forma vale por si. E mais ainda, onde é certo que existe uma aprovação pública que recai e com razão na maioria das vezes sobre a qualidade formal do edifício. Este entendimento é ainda reforçado pelo facto desses museus corresponderem a vontades mais políticas que culturais e disporem de verbas particularmente elevadas. Pensamos no caso do Museu de Bilbau cujo conteúdo é claramente secundário face à sua embalagem. O interesse que desperta resulta no essencial da qualidade formal do edifício.

Um outro caso paradigmático é Museu de Arte Moderna de Niteroi, no qual as mais elementares funções museológicas não estão asseguradas. E quem lá trabalha que o diga, pois nenhuma área de serviço dispõe de condições mínimas de funcionalidade e de salubridade.

E no entanto, do ponto de vista arquitectónico, se reconhece a elevada qualidade.

No campo da adaptação de edifícios para funções museológicas a situação é na essencial oposta pois o projecto tem geralmente por base um programa e corresponde a necessidades decorrentes da acção museológica. Se os museus novos são de 
origem ministerial estes segundos são de origem municipal ou privada. Mas também é certo que muitas vezes o importante é inaugurar uma obra fruto de calendários eleitorais deixando para depois a definição da sua utilidade.

Quanto aos projectos expográficos, o papel da arquitectura é geralmente negligenciado, resultando de decisões mais ou menos fundamentadas dos responsáveis por cada exposição. A memória de exposições anteriores acaba por condicionar os novos projetos perdendo-se a possibilidade de valorizar cada exposição com o contributo da arquitectura. Mas verdade seja dita perdendo também a possibilidade de valorizar cada exposição com 0 contributo de outras áreas do conhecimento. O oposto também é válido se considerarmos que também existem situações onde o arquitecto pretende sobrepor a organização espacial ao próprio conteúdo da exposição. Em ambos os casos importa por em realce a ausência de diálogo inter-áreas do conhecimento no projecto tanto de edifícios (novos ou adaptações) como nos projectos expográficos.

Esta falta de diálogo em nosso entender resulta de um desconhecimento do contributo que cada área do conhecimento pode trazer para o campo da museologia.

Quer se trate de museus tradicionais que preservam e exibem as suas coleções para múltiplos fins incluindo a educação o lazer, ou quer se trate de museus sustentados conceptualmente na Sociomuseologia e por isso envolvidos com os conceitos de desenvolvimento, território, participação e inclusão social, em ambos os casos podem ser entendidos como organizações prestadoras de serviços, também configuradas com as expectativas dos seus públicos, utilizadores e beneficiários e indirectos.

Os contornos, os conceitos e as práticas da museologia têm passado por transformações profundas que têm colocado os Museus na Europa e no Mundo no centro da vida económica cultural e social. Também isso é verdade para a arquitectura que tem novos contornos, novos conceitos e novas práticas que expressam transformações profundas que têm colocado a 
arquitectura na Europa e no Mundo no centro da vida económica cultural e social.

Então é tempo de aprofundar o diálogo entre estas duas áreas do conhecimento de modo que possam contribuir de forma articulada para uma melhor arquitectura e uma melhor museologia.

\section{Bibliografia}

Appadurai, Arjun. (2004). "As dimensões Culturais da globalizaçãof. Lisboa, Teorema.

Bruno, Maria Cristina (2004). 'As expedições no Cenário M useal, in Expedição são Paulo 450 anos, São Paulo, M useu da Cidade de São Paulo, pp 36

Krauel, Jacobo (2013) New concepts in museums architecture, Links International, ISBN-10: 8492796995

Leite, Pedro Pereira e Primo, Judite (2019). 'The Role of Cultural Diversity for Sustainable Communities in CAM OC Frankfurt Proceedings, Frankfurt, pp 144-150.

Moutinho, M. M useus e Sociedade, M onte Redondo, Edições do Museu de Monte Redondo. 1990, pp.150

Moutinho, Mário, 1979. A Arquitectura Popular Portuguesa, Editorial Estampa, lisboa 1979, pp

Rico, Juan Carlos, (2011) Museos. Del Templo Al Laboratorio, Editor: SILEX. pp.340 ISBN: 9788477374534

Rico, Juan Carlos, (2009) Los Conocimientos Tecnicos. Museos, Arquitectura Y Arte, SILEX, pp.640, ISBN: 9788477372189

Rico, Juan Carlos, (2006) Manual Practico De M useologia, M useografia Y Tecnicas Expositivas, SILEX, pp.251, ISBN: 9788477371687

Self, Ronnie, (2014) The Architecture of Art M useums: A Decade of Design: $2000 \pm 2010$, Routledge, pp.297, ISBN-10: 0415506522

Uffelen, Chris van, (2010). Contemporary Museums: ArchitectureHistory-Collections, Braun, pp.512, ISBN: 303768067 